This is an electronic reprint of the original article. This reprint may differ from the original in pagination and typographic detail.

Author(s): Ojala, Arto; Puhakka, Vesa

Title: $\quad$ Opportunity Discovery and Creation in Cloud Computing

Year: $\quad 2013$

Version:

Please cite the original version:

Ojala, A., \& Puhakka, V. (2013). Opportunity Discovery and Creation in Cloud Computing. In 46th Hawaii International Conference on System Sciences (pp. 42944303). IEEE Conference Proceedings. Proceedings of the Annual Hawaii International Conference on System Sciences. https://doi.org/10.1109/HICSS.2013.431

All material supplied via JYX is protected by copyright and other intellectual property rights, and duplication or sale of all or part of any of the repository collections is not permitted, except that material may be duplicated by you for your research use or educational purposes in electronic or print form. You must obtain permission for any other use. Electronic or print copies may not be offered, whether for sale or otherwise to anyone who is not an authorised user. 


\section{Opportunity Discovery and Creation in Cloud Computing}

\author{
Arto Ojala \\ University of Jyväskylä \\ arto.k.ojala@jyu.fi
}

\author{
Vesa Puhakka \\ Univerisity of Oulu \\ vesa.puhakka@oulu.fi
}

\begin{abstract}
Cloud computing provides opportunities for firms selling or using cloud services. However, little is known about how entrepreneurs discover or create these opportunities for cloud computing. In this study, we found that the opportunities discovered in cloud computing were related to the development of software for a particular need. By contrast, created opportunities were developed under conditions of technological uncertainty, at a time when the market did not yet exist. It appears that created opportunities, if successful, bring long-term competitive advantages, whereas discovered opportunities are more easily copied and exploited by competitors.
\end{abstract}

\section{Introduction}

Over the last decade, increasing scholarly attention has been paid to cloud computing and software-as-a-service (SaaS). It has been shown that cloud computing and related services can bring about important technical benefits and business advantages $[5,6,17,20,34]$. The studies in question have mainly focused on the opportunities provided by cloud services, and not on how these opportunities can be recognized and exploited. Thus, little is known about how software entrepreneurs discover or create opportunities for the provision of cloud services, or how they recognize opportunities to adapt their existing product for a cloud service model. Finding an answer to these questions is important for software entrepreneurs working in the industry, since the cloud computing is growing rapidly and offers a good arena for new business opportunities. Cloud computing also creates new jobs and promotes growth in the software and other related industries [38].

Research on entrepreneurship offers two distinct theories on how opportunities come to be recognized. The first theory, opportunity discovery, sees opportunities as existing independently of entrepreneurs, and as objective phenomena that are waiting to be discovered and exploited [2]. Thus, opportunities exist and everyone could become aware of them; however, individual differences, such as prior knowledge, entrepreneurial activeness, alertness, and willingness to bear a risk, impact on who will discover and exploit the opportunities [19, $29,33]$. The second theory, opportunity creation, is based on entrepreneurial perceptions, imagination, and social interaction $[2,27]$. In contrast to opportunity discovery, in opportunity creation the opportunities do not exist independently of the entrepreneurs: they are created endogenously by the actions of entrepreneurs who are seeking to explore new products or services. Thus, there is no opportunity "waiting to be recognized"; instead an entrepreneur may create the opportunity and observe how customers and markets respond to the created product or service [2].

Building on previous work on cloud computing, and drawing insights from opportunity recognition theories, the aim of this article is, first of all, to reveal how opportunities for cloud computing are recognized, and in so doing contribute to the growing body of academic literature on cloud computing. Secondly, we wish to contribute to two entrepreneurship theories, opportunity discovery and opportunity creation, through an empirical examination of their capability to explain opportunity recognition in the context of cloud computing. In addressing these issues, the following research questions are addressed: (1) How are the opportunities for cloud computing discovered and created? (2) What are the differences between discovered and created opportunities in cloud computing?

\section{Literature review}

\subsection{Opportunities provided by cloud services}

In cloud computing, users obtain access to computing resources, storage space, and software applications via the Internet as a service. Cloud computing includes three service layers. These consist of (i) Infrastructure as a Service (IaaS), which provides computation and storage capacity, (ii) 
Platform as a Service (PaaS), which provides software development tools plus an application execution environment, and (iii) SaaS, which provides applications on top of PaaS and IaaS [5]. Thus, cloud computing refers to the provision of computing capacity, storage capacity, and applications as a service across the Internet. The International Data Corporation (IDC) defines cloud computing as "consumer and business products, services and solutions delivered and consumed in real-time over the Internet" [37].

Most of the literature on cloud computing and SaaS has taken a practical perspective on the general opportunities provided by cloud computing $[5,17$, 20, 33, 36]. Armbrust et al. [5] present six opportunities provided by computing in public clouds as compared to conventional data centers. In addition, they highlight ten obstacles related to cloud computing, plus means of avoiding these obstacles. McAfee [20] sets out the following benefits available from a cloud service: (i) it makes individuals more productive, (ii) it facilitates collaboration, (iii) it makes possible insights from a large amount of data, and (iv) it facilitates development and hosting applications. McAfee [20] also presents four guidelines on how entrepreneurs could move their product offering to the cloud. These guidelines include: (i) identification of restrictions and gray ideas, (ii) the acquisition of experience from cloud services, (iii) the development of trial versions for the cloud, and (iv) sharing the idea of a cloud service with colleagues and software vendors. Waters [34] presents the opportunities available from cloud services from the customer's point of view, comparing the cloud model with the traditional software delivery and sales model. According to his findings, cloud services can lead to lower IT expenses, faster implementation, and contractually guaranteed reliability and security.

Zhang et al. [36] discuss the general opportunities and challenges pertaining to cloud computing, and compare the opportunities permitted by three different commercial cloud products. Iyer and Henderson [17] present seven capabilities of cloud computing related to cost reduction and organizational agility. These capabilities are: a controlled interface, location independence, sourcing independence, ubiquitous access, virtual business environments, addressability and traceability, and rapid elasticity. Benlian and Hess [6] studied IT executives' perceptions of the opportunities and risks of SaaS. They found that security threats were the most dominating factor in risk perception, whereas the cost advantages of SaaS were the strongest driver for SaaS adoption.
The studies above focused mainly on the general advantages of cloud services, either from the software provider's or the customer's point of view. However, there has also been work on more specific research topics. Thus, Böhm et al. [7] and Ojala and Tyrväinen [23] studied value networks in cloud computing, that is, how cloud computing brings value and opportunities for the actors in a firm's network. Böhm et al. [7] developed a generic value network for cloud computing; this could help entrepreneurs to position their firm in a value network and identify possible business opportunities. Ojala and Tyrväinen [23] described how a cloud service provider's value network can develop over a five-year period, and the kinds of opportunities available to the cloud service provider through cooperation between different actors. Choudhary [9] examined the opportunities enabled by software renting in the SaaS delivery model. He found that software renting in the SaaS model leads to greater investments in product development and consequently higher software quality. Cloud computing has also opened up opportunities for new types of services such as Gaming-as-a-Service [18, 24], Business-Processingas-a-Service [1], Music-as-a-Service [12], and so on.

Overall, previous research has highlighted cloud computing as a promising area providing opportunities, for example, for improved efficiency, new customer value, and the reorganization of the entire value creation network. This takes us to the question of how these opportunities can be discovered and/or created through entrepreneurial behavior.

\subsection{Opportunity discovery and creation}

Referring to opportunity discovery, Eckhardt and Shane [13, p. 336) define opportunity as "situations in which new goods, services, raw materials, markets and organizing methods can be introduced through the formation of new means, ends, or means-ends relationships." This definition is based on the assumption that an opportunity is a situation in which new combinations producing economic value can be formed, and in which the elements used fundamentally exist already. Different types of opportunities exist because opportunities occur as a result of changes in different parts of the value chain. An alternative view, presented by Sarasvathy et al. [28], refers to opportunity creation, defined as "a set of ideas, beliefs and actions that enable the creation of future goods and services in the absence of current markets for them" [28, p. 79]. In this case opportunity arises from perceptions and behaviors combined in an attempt to create new economic 
artifacts. The emphasis is on actions taken in a situation of true entrepreneurial uncertainty. These two views will be looked at in more detail below.

The opportunities to be discovered can arise from exogenous shocks, for example industry or market changes beyond the influence of entrepreneurial action; these exist regardless of whether people are aware of their existence [2]. Hence, opportunities arise through new means, ends, or means-end frameworks [13], and they can be conceived as discovered opportunities. They involve the possibility of putting resources to better use or discovering new solutions or new needs, plus identifying the most suitable options for their realization [28]. There will be either a solution or a need operating as a starting point. Discovered opportunities are recognized through active search behavior, but the discovery process is not simple. The opportunities in question are typically complex entities, and their discovery is a process in which new features are added to the opportunity content [4]. In discovered opportunities the emphasis is on resource allocation and use in the initiation of the business.

Created opportunities, on the other hand, do not exist independently of social construction; rather, they are enacted through human imagination and social interaction as a continuous process $[2,3]$. The opportunity appears within a flexible activity of creating meaning, sense-making, and sense-giving in an ambiguous social context $[8,10]$. Instead of being actively sought out, the opportunities are endogenously formed in the very unfolding of everyday entrepreneurial practice and interactions between various actors [11, 28, 31]. Created opportunities are connected with true uncertainty, in which neither supply nor demand exists and the future is unknowable [28]. Entrepreneurs engage in a learning process marked by a gradual investment of resources and attempts to persuade others to change their vague and unformed aspirations into tangible products or services, or new markets [2].

Taken as a whole, previous research has tended to argue that the characterization of discovered and created opportunities involves both contradictory and complementary views. Alvarez and Barney [2] see discovered and created opportunities as representing different views that can barely co-exist. Chiasson and Saunders [8], for their part, see discovery and creation as complementary approaches, while Vaghely and Julien [32] propose an integrative framework which connects opportunity discovery and opportunity creation within entrepreneurial behavior. Edelman and Yli-Renko [14] have found empirical evidence that discovery and creation are intertwined within entrepreneurial action.

\subsection{Summary}

From the literature, we can conclude that opportunities in cloud computing have been well studied from both the service provider's and the user's point of view. However, we do not know how entrepreneurs discover or create the opportunities related to the different layers (SaaS, PaaS, and IaaS) of cloud computing. Furthermore, there is still a lack of knowledge concerning the differences between discovered and created opportunities in cloud computing, and the ways in which these opportunities can benefit entrepreneurs in terms of bringing new products and services to the market.

\section{Methodology}

The research method selected for this study had to cover a real-life environment containing an instance or instances of opportunity recognition. Thus, we used a case study methodology similar to the approaches presented by Eisenhardt [15] and Yin [35]. The case study method is appropriate in a situation where the study covers a real-life environment [35] involving an action such as opportunity recognition. Along similar lines, Shane $[29$, p. 453] argues that the case study method allows the investigation of how opportunity recognition operates in situations where "all of the relevant behaviors cannot be manipulated through experimental design." Thus, our aim was not to achieve statistically generalizable findings. Instead, we wanted to find the reasons behind certain entrepreneurial behaviors in the context of cloud computing.

The research setting for this study consisted of four software firms (see Table 1) who acted as cloud service providers. Since the sample used will necessarily influence the results of the study [21], we used multiple criteria to select the cases. Three of the firms were dealing with a national cloud software program in Finland, while one firm was contacted on the basis of knowledge of the industry on the part of one of the authors. Thus, the most important selection criterion was good access to the required information, as recommended by Stake [30]. The personal-contact aspect increased mutual trust between the researcher and the persons interviewed in the case firms, and consequently facilitated the collection of accurate information. Note, however, that the selection of cases cannot be based solely on good access to information, and that the theoretical perspective must also be also taken into account [15]. From the theoretical point of view the following aspects were seen as relevant: (i) the case firms were developing 
their cloud services for different industries, (ii) the sample included both relatively old firms and recently established firms, and (iii) the source providing cloud computing opportunities was different in all cases.

Table 1. Overview of the case firms

\begin{tabular}{|l|l|l|l|l|}
\hline Firm & $\begin{array}{l}\text { Number of } \\
\text { employees }\end{array}$ & $\begin{array}{l}\text { Year of } \\
\text { establishment }\end{array}$ & Product(s) & Target industry \\
\hline Firm A & 30 & 1998 & $\begin{array}{l}\text { Planning and optimization software } \\
\text { for telecom operators }\end{array}$ & $\begin{array}{l}\text { Telecom operators, } \\
\text { Component manufacturers and service } \\
\text { providers for telecom networks }\end{array}$ \\
\hline Firm B & 25 & 2000 & $\begin{array}{l}\text { Gaming platform and gaming } \\
\text { content }\end{array}$ & Telecom operators and game players \\
\hline Firm C & 12 & 2008 & Entitlement management software & Large and medium-sized corporations \\
\hline Firm D & 30 & 2006 & Interactive 3D sales software & $\begin{array}{l}\text { Furniture chains and furniture } \\
\text { manufacturers }\end{array}$ \\
\hline
\end{tabular}

This kind of coverage is important for studies in which the sample is small and the general aim is to include "polar types" of research sites [25].

We used multiple sources of information to gather data on each case firm. The main form of data collection was in-depth interviews. Altogether, we conducted 4-8 interviews per firm, each lasting 4590 minutes. Thus, 18 semi-structured open-ended interviews were conducted in total. The interviewees consisted of Chief Executive Officers (CEOs), sales managers, vice presidents, members of the board of directors, and software engineers. The interviews with the CEOs were the main source of information. During the first interview, we collected general information about the firm, its products, customers, business models, etc. In the second and subsequent interviews, we used more structured interview guidelines, based on the information gathered in the previous interview(s). These subsequent interviews focused on the opportunity recognition in detail. Because the interviews touched on the interviewees' past experiences, we followed the guidelines for retrospective studies issued by Miller et al. [22] and Huber and Power [16]. For instance, if an interviewee was unsure about an important event, we asked the interviewee to check his/her emails to recall how the events progressed. This worked well, as all the interviewees had saved past emails. We recorded all the interviews, and the first author personally transcribed them verbatim, using a word processing program. Thereafter, the complete transcripts were sent back to the interviewees for review. For the most part the interviewees accepted the transcripts in the form in which we sent them. However, in some cases, the interviewees gave some minor comments related to the misspelling of a partner's name or to some particular wording. In addition to the face-toface interviews, telephone and e-mail communication was used to collect further information, and to clarify inconsistent issues if necessary. These communications were also added to the case-study database. By comparing the interview data with other information gathered on the case firms, we conducted triangulation of the information [21].

In addition to the actual interviews, we had several informal discussions with interviewees during seminars and in spare time. These informal discussions were useful in terms of collecting further information and clarifying the business processes of the firms. In the data collection, we also used many types of secondary information such as press releases, websites of the firms, brochures, etc. to collect the kind of information that could validate the data gathered in the interviews. Table 2 gives an overview of the data sources.

The method utilized in the data analysis was content analysis. The analysis of the case data consisted of three concurrent flows of activity [21]: (i) data reduction, (ii) data displays, (iii) conclusiondrawing/verification. In (i) the data reduction phase, the data were given focus and simplified through compilation of a detailed case history of each firm. This is in line with Pettigrew [25], who suggests that organizing incoherent aspects in chronological order is an important step in understanding the causal links between events. Thereafter, on the basis of the interviews and other material collected from the case firms, we used tables to identify and categorize the unique patterns of each case under sub-topics derived from the research questions. In addition, we used checklists and event listings to identify critical factors related to the phenomena encountered [21]. In (ii) the 
data display phase, we arranged the relevant data, drawn from the findings of the previous phase, into new tables. In (iii), the phase of conclusion-drawing and verification, we concentrated on identifying the aspects that appeared to have significance for this study. At this stage we noted regularities, patterns, explanations, and causalities related to the phenomena.

Table 2. Overview of the data sources

\begin{tabular}{|c|c|c|c|c|c|c|}
\hline Firm & $\begin{array}{l}\text { Interviews with } \\
\text { the CEO }\end{array}$ & $\begin{array}{l}\text { Number of other } \\
\text { persons interviewed }\end{array}$ & $\begin{array}{l}\text { Total number of } \\
\text { interviews }\end{array}$ & Web pages & Brochures & Press releases \\
\hline Firm A & 1 & 3 & 4 & $\mathrm{X}$ & $\mathrm{X}$ & \\
\hline Firm B & 4 & 1 & 5 & $\mathrm{X}$ & $\mathrm{X}$ & $\mathrm{X}$ \\
\hline Firm C & 2 & 2 & 4 & $X$ & & $\mathrm{X}$ \\
\hline Firm D & 2 & 3 & 5 & $\mathrm{X}$ & $\mathrm{X}$ & \\
\hline
\end{tabular}

\section{Findings}

The findings are presented in this section as individual case descriptions. Their relation to the theory and to previous literature is elaborated in the discussion section.

\subsection{Case descriptions}

Firm $A$ offers professional services and a software product for telecom operators to assist in their cellular network planning and optimization activities. The firm, established in 1998, acted purely as a service firm until 2009, when it started to develop its own software product. Currently, it provides both consultant services and a related software product. Before it developed its own software, Firm A used products that were already in the market. However, its employees and customers were not happy with these because of poor usability, problems with software administration, and a lack of the functionalities needed. In addition, the existing products were very complex and targeted only at engineers, even though the information dealt with was relevant to other actors as well. The CEO of Firm A explained the situation in the following manner:

"We had employees who used existing software products in our projects and they realized the kinds of problems there were in running these programs. Consequently, we started to think about finding an easier, practical, and modern way to do it."
With these considerations in mind, the entrepreneur of Firm A realized that the personnel in the firm could use their existing knowledge from earlier customer projects and experiences while working on existing products; at the same time they could seek to develop new and better software. In addition to the fact that they needed the software to carry out their own projects, they saw the potential of selling the software to telecom operators and firms offering corresponding services. The people in Firm A thus started to develop the product so that it would be easy to use for all parties involved in projects for network planning and optimization. They also included a time management tool within the software. Most importantly, the software was available in a cloud over the Internet connection, giving all participants in a project easy and instant access to the software. The entrepreneur and CEO of Firm A explained this as follows:

"The most important thing was that it is easily available. Thus, we do not need to send our employees to install it in an operator's office and carry out what are sometimes complex IT processes in conjunction with the customer's IT organization. When it is available in the SaaS model, the customer can start using it right away"

Because the software was used mainly in project working, the SaaS model also increased its effectiveness in group work. Furthermore, Firm A saw that new software products were moving increasingly to the SaaS model. By contrast, the existing products that they used required installation from CD-ROM to PC plus purchase of a costly software license. In other words, the products were 
not available via rental or pay-per-use models. Thus, the entrepreneur of Firm A saw cloud computing as a good way to differentiate the firm's product range from that of competitors who did not have products available through the SaaS model.

Firm B, established in 2000, provides interactive gaming platforms and games-on-demand services. Before establishing his own firm, the entrepreneur of Firm B was working in a company that developed videoconferencing equipment and related software for PCs. During this work, he learnt about streaming technology and got to know network operators and their business strategies. The idea for the new product and firm was created in collaboration between the entrepreneur and a friend - someone who acted as a "business angel" and who knew people working in the games industry. The first idea was develop a gaming platform that operated in a cloud and would be targeted at 3G mobile phones. In 1999 the telecom operators were planning to launch $3 \mathrm{G}$ networks, and preconceptions about the network and its capacity were optimistic. However, the partners in Firm B also realized that the computing capacity of mobile phones was relatively low and that there would be several models of mobile phones using different operating systems. In addition, the life cycle of mobile phones is short. All of these factors made it difficult to develop good games with advanced features for mobile phones. To resolve this challenge, the co-founders of Firm B started to develop a platform that would make it possible to send game content over the $3 \mathrm{G}$ network as an MPEG stream from a server to mobile phones, with players' commands being sent back to the server operating the game. The entrepreneur described the market situation in the following way:

"In $19993 G$ networks and $3 G$ mobile phones were coming onto the market. We realized that it would be a huge challenge to develop good games for mobile phones because there were several mobile phone manufacturers developing mobile phones, all of which would be different. We thought that instead of running games on mobile phones, we could run the games on a server that would encode the gaming content in real time to an MPEG stream and send it to the mobile phone, which would recode and show the game. Thus, it would be enough if a mobile phone could encode and recode a bit-stream."

Quite soon the co-founders realized that the development of $3 \mathrm{G}$ networks was not as fast as predicted, and that the $3 \mathrm{G}$ network was not reliable enough to handle the bit-stream without latency. Consequently, they started to develop the platform so that it could be used to deliver gaming content for PCs or IPTVs over the broadband network. In its current business model, Firm B licenses game content from game developers and converts these games to its gaming platform. The network operators operate the platform and deliver games to players' set-top boxes or PCs through their broadband network. This delivery model presents a totally new way to offer game content as a cloud service, and offers a good way to differentiate the product from the traditional game offering.

Firm $C$ was launched in 2008 as a spin-off from a software service firm that provides consulting services related to identity management. Currently, Firm C develops SaaS solutions for entitlement management, mainly for the financial sector. The idea for a new product came from a consulting firm's large customer. This was a firm in which the entrepreneur of Firm $\mathrm{C}$ had worked previously. The customer in question needed software that would help in administering the increasing amount of access rights that were being granted to external users of the IT services provided by the company and its subsidiaries. The consulting firm had done some work on a new architecture by which access rights could be administered in a centralized manner. Subsequently, the customer asked whether the consultancy firm could develop software for precisely this purpose. The consultancy firm started to develop and sell its product in parallel with its consultancy business; however, some of the firm's customers saw a conflict of interest in this situation. The entrepreneur commented on this as follows:

"Some of the customers said that you can't have the product if you do consultancy work at the same time. They were worried that we would sell our own solution whether it or not it was the best solution for the customer's problem."

Based on these considerations, the entrepreneur established Firm C. The firm continued the development and marketing of entitlement management software. Many of its existing or potential customers were use-to-use outsourced IT services, the reason being that these services do not have their own data centers or specialized IT personnel. Thus the product had to be built so that it would work as a hosted service within a service provider's data center. In addition, it had to be able to solve customers' identity management problems for both internal and external users in a centralized manner. In many cases, the customers also liked to give these tasks to their own business customers. The entrepreneur of Firm $\mathrm{C}$ saw that the SaaS model 
could address these aspects. The SaaS model also helped the firm to differentiate its product from corresponding solutions in the market. The entrepreneur explained the benefits of SaaS as follows:

"As an Saas product, our software is considerably different from other products in the market. By using it, companies can provide identity management for their customers, and these customers can pass it on to others if required. It is faster, cost effective, and the user experience is better."

Firm D, founded in 2006, develops interactive 3D sales software platform for furniture manufacturers and furniture retailers. Firm D also models customers' furniture elements for their 3D software, and encodes rules for how different furniture elements can be attached to each other. The software is divided into four different packages so that the first, the "basic" package, includes only basic functionalities, and the fourth package is the most advanced. The establishment team of Firm D includes four persons. These were all previously working at a firm that developed 3D modeling software as one software product among a wider product portfolio. Their previous employer had tried to use 3D modeling software for various industries that might benefit from the software, but it had not been possible to find the right target. Consequently, the employer had given up the development of the software and had started to focus on the firm's core business. At the same time, some of the employees had seen the real potential of the product. They thus established Firm D. The aim was that Firm D would develop the product further, focusing on the furniture industry. The co-founder and CEO of Firm D explained this as follows:

"The idea of the product comes from the previous firm, where we tried various business segments in which customers could use $3 D$ modeling and visualization. However, everything we tried failed somehow. It was difficult to find the right segments for the product. Of course, it was a large firm, and because they had other, more successful products they started to plan to shut down the development of the $3 D$ product. At the same time, we saw that the market was starting to be ready for this product, and we got our first customers."

The vice president of Firm D commented on the selection of the target industry as follows:
"We saw that the furniture industry was at a turning point in which they were not receiving benefits from IT tools, but we showed them that there was a real need for this type of product. On the other hand we saw that it was good to have a clear niche area for the product so that we could quickly bring added value for our customers."

The first idea was to sell the product for each customer's Intranet as packaged software. However, quire soon the people in firm D realized that the customers did not care where the product might be running, and some of the potential customers, especially the smaller ones, did not have the Intranet. In addition, they realized that the software should be available through the Internet so that customers could use the software wherever they were located, and could further offer access to the software to their own customers. Thus, the SaaS model proved to be the right choice for bringing the product quickly to the market. It also enabled use of the software by smaller customers who did not have their own Intranet, or who lacked the IT infrastructure or resources to buy a costly software license. This also helped Firm D to differentiate its product offering from competitors, as the competitors mainly used CAD-based programs that were not available via the SaaS model.

\section{Discussion of the results}

From the observations made in the study, it appears that the case firms used either opportunity discovery (Firms A, C, and D) or opportunity creation (Firm B) to develop new cloud computing services. The entrepreneur of Firm A had been dissatisfied with the existing products in the market. The prior knowledge and experience of the entrepreneur and his co-founders in the telecommunications market led to the discovery of an opportunity - in this case involving a new software product via the SaaS model. This is in line with the findings of Shane [29], who noted that prior knowledge has an important role in opportunity recognition; it determines why not everyone is equal in terms of recognizing the same opportunities based on technological change. In the case of Firm $\mathrm{C}$, the opportunity discovery was based on the customer's need, and the entrepreneur's discovered solution for this need. The SaaS model made it possible to solve a specific customer need, involving in this case centralized administration. Thus, the discovered opportunity was based on alertness rather than on an active search. According to Ray and Cardozo [26], entrepreneurial alertness makes some people more sensitive to information about objects and about 
users' needs, and it is this sensitivity that can lead to the discovery of opportunities.

The co-founders of Firm D got the idea for their product from a previous employer. However, using both an active search and prior knowledge (cf. [29]), they discovered the opportunity to focus on one specific industry. Here there was a clear need for the software that they were able to provide. In Firm D's case, the SaaS model gave customers better access to the software, and also allowed availability for smaller customers. Altogether, the case firms (A, C, and D) who followed the path of opportunity discovery saw a clear demand in the market for a product that they were able to provide. They then met this demand. The provision was based on dissatisfaction with existing products (Firm A) or on customers' needs (firms C and D). All in all, as argued by Sarasvathy et al. [28], there was a possibility to discover a new solution for a certain need.

The opportunity recognition of the co-founders of Firm B clearly involved created opportunities. Working collaboratively, they used entrepreneurial perception, imagination, and prior knowledge to create the product, even though there was no demand for the product from customers (cf. [27, 28]) The entrepreneurs also acted in a state of uncertainty; in fact, the market for the product did not yet exist and the technology that would enable usage of the product was still unsure. The product was targeted at $3 \mathrm{G}$ networks that were under development at the time when the opportunity was created. This is in line with Sarasvathy et al.'s [28] notion that created opportunities are based on uncertainty - a situation in which the demand does not exist, and in which the future is unknowable. The entrepreneurs of Firm B also kept an eye on the development of the technology and the markets. When they realized that the capacity of $3 \mathrm{G}$ networks would never become fast enough for their product, they changed their strategy accordingly, and started to develop the product for the PC and IPTV markets. Thus, they focused on the controllable aspect of an unpredictable future (cf. [27]), without having clear targeting or segmentation goals. In line with Alvarez and Barney [2] they observed how customers and markets were developing, envisaged certain possibilities, and created an opportunity accordingly.

The findings indicate that opportunity discovery was mainly related to the improvement of an existing product to solve customers' problems or needs. The improvements were mainly executed by adding some features of cloud computing to the product. This also helped the case firms to differentiate their product offering from equivalent non-SaaS products already in the market. Hence, the firms that discovered opportunities for cloud computing saw the advantages of the SaaS model (such as location independence, flexible pricing, and centralized administration) as a way to develop their product and further enhance their competitive position. In contrast, Firm B, which used opportunity creation, did not improve any existing product; instead they created a totally new product, based on the possibilities offered by cloud computing. In both opportunity discovery and creation, prior knowledge was important. However, active search and alertness were the features uppermost in the opportunity discovery.

The case studies suggest that that opportunity discovery in cloud computing brings only short-term competitive advantages, whereas opportunity creation can bring about more long-term advantages. Discovered opportunities were regarded as solutions for existing needs in the market, and were more or less visible to all actors. In fact, anyone with the relevant prior knowledge of the technology and the markets, and with sufficient alertness and activeness to search for these opportunities, could have made and exploited the discovery. In addition, the discovered opportunities for cloud computing are relatively easy to observe and copy. This makes it easy for competitors to transform their corresponding products in line with the SaaS model. In contrast, created opportunities can bring long-term competitive advantages, since they are not targeted at a welldefined problem in the market. Thus, when a firm creates the need for the product, it can achieve firstmover advantage. The firm can also develop network relationships with suppliers and customers before competition emerges. This makes it more difficult for potential competitors get into the pre-established networks and to acquire a position in the market. It also increases customers' switching costs.

\section{Conclusions}

This study contributes to research on cloud computing by demonstrating how opportunities for cloud computing are discovered and created. The study further reveals differences between discovered and created opportunities in the context of cloud computing. We found that discovered opportunities were related to the development of a product for a specific need, whereas created opportunities were developed under conditions of technological uncertainty, for markets that did not yet exist. In opportunity discovery, entrepreneurs added features of cloud computing for existing products in an attempt to solve customers' problems, whereas in opportunity creation the product was developed on 
the basis of the advantages brought by cloud computing. It can be argued that created opportunities, if successful, bring long-term competitive advantages whereas discovered opportunities are more easily copied by competitors.

To summarize the above from the managerial point view, three features define the opportunities in question. Firstly, the strong vision of the entrepreneur(s) inside and outside an organization acts as an initiator of the entire process of discovering or creating opportunities, and lays down a guideline that steers the process during the development of the opportunity. Secondly, the activities of combining knowledge and incorporating feedback into the development of an opportunity by combining people's different backgrounds, and by incorporating feedback from partners, customers, and others, entrepreneurs are able to utilize the complementary factors of knowledge and information. The final feature is the communication of the opportunity to external actors and to the environment. This is especially important for created opportunities, which are directly related to the entrepreneur and are not objectively observable in the environment. The entrepreneur must be able to communicate the benefits, promises, and values of the opportunity to surrounding actors, in order for the opportunity to be perceived as interesting and attractive for all concerned.

\section{Acknowledgements}

The research reported in this paper was carried out within the framework of the Cloud Software Program which was governed by TIVIT Oy nominated to organize and manage the programs of the Strategic Center for Science, Technology and Innovation in the field of ICT funded by the Finnish Funding Agency for Technology and Innovation (TEKES). In addition, the authors would like to thank financial support from Finnish Foundation for Economic Education for this study.

\section{References}

[1] Accorsi, R. 2011. Business Process as a Service: Chances for Remote Auditing. Computer Software and Applications Conference Workshops (COMPSACW), 2011 IEEE 35th Annual Conference.

[2] Alvarez, S.A., Barney, J.B. 2007. Discovery and creation: alternative theories of entrepreneurial action. Strategic Entrepreneurship Journal 1(1-2), 11-26.

[3] Alvarez, S.A., Barney, J.B. 2010. Entrepreneurship and Epistemology: The Philosophical Underpinnings of the Study of Entrepreneurial Opportunities. The Academy of Management Annals 4(1), 557-583.
[4] Ardichvili, A., R. Cardozo, and S. Ray 2003. 'A theory of entrepreneurial opportunity identification and development,' Journal of Business Venturing, 18(1), 105-123.

[5] Armbrust et al., 2010. A view of cloud computing. Communication of the ACM, 53(4), 50-58.

[6] Benlian, A., Hess, T. 2011. Opportunities and risks of software-as-a-service: Findings from a survey of IT executives. Decision Support Systems, 52(1), 232246.

[7] Böhm et al. 2010. Towards a Generic Value Network for Cloud Computing, In Altmann, J. and Rana, O. (Eds.) Economics of Grids, Clouds, Systems, and Services. Springer, Berlin. 129-140.

[8] Chiasson, M., Saunders, C. 2005. Reconciling diverse approaches to opportunity research using the structuration theory. Journal of Business Venturing, 20(6), 747-767.

[9] Choudhary, V., 2007. Comparison of Software Quality Under Perpetual Licensing and Software as a Service. Journal of Management Information Systems, 24(2), 141-165.

[10] Cornelissen, J., Clarke, J. 2010. Imagining and Rationalizing Opportunities: Inductive Reasoning and the Creation and Justification of New Ventures. Academy of Management Review, 35(4): 539-557.

[11] De Clercq, D., Voronov, M. 2009. Toward a Practice Perspective of Entrepreneurship: Entrepreneurial Legitimacy as Habitus. International Small Business Journal, 27(4): 395-419.

[12] Doerr, J., Benlian, A., Vetter, J., Hess, T. 2010. Pricing of Content Services -An Empirical Investigation of Music as a Service. In Nelson et al. (eds) Sustainable e-Business Management, Lecture Notes in Business Information Processing, Springer, $13-24$.

[13] Eckhardt, J.T., Shane, S. 2003. Opportunities and Entrepreneurship. Journal of Management, 29(3), 333349.

[14] Edelman, L., Yli-Renko, H. 2010. The Impact of Environment and Entrepreneurial Perceptions on Venture-Creation Efforts: Bridging the Discovery and Creation Views of Entrepreneurship. Entrepreneurship Theory and Practice, 34(5), 833-856.

[15] Eisenhardt, K.M. 1989a. Building Theories from Case Study Research. Academy of Management Review, 14(4): 532-550.

[16] Huber, G.P., \& Power, D.J. 1985. Retrospective Reports of Strategic-level Managers: Guidelines for Increasing their Accuracy. Strategic Management Journal, 6, 171-180.

[17] Iyer, B., Henderson, J.C., 2010. Preparing for the Future: Understanding the Seven Capabilities of Cloud Computing. MIS Quarterly Executive, 9(2), 117-131.

[18] Jarschel, M., Schlosser, D., Schuring, S., Hoßfeld, T., in press. Gaming in the clouds: QoE and the users' perspective. Mathematical and Computer Modelling.

[19] Kirzner, I.M. 1979. Perception, Opportunity, and Profit: Studies in the Theory of Entrepreneurship. Chicago: University of Chicago Press. 
[20] McAfee, A., 2011. What Every CEO Needs to Know About The Cloud. Harvard Business Review, 89(11), 124-132.

[21] Miles, M.B., \& Huberman, A.M. 1994. Qualitative Data Analysis: An Expanded Sourcebook. California: Sage Publications.

[22] Miller, C.C., Cardinal, L.B., \& Glick, W.H. 1997. Retrospective reports in organizational research: A reexamination of recent evidence. Academy of Management Journal, 40(1): 189-204.

[23] Ojala, A., Tyrväinen, P., 2011a. Value networks in cloud computing. Journal of Business Strategy, 32(6), 40-49.

[24] Ojala, A., Tyrväinen, P., 2011b. Developing Cloud Business Models: A Case Study on Cloud Gaming. IEEE Software, 28(4), 42-47.

[25] Pettigrew, A.M., 1990. Longitudinal Field Research on Change: Theory and Practice. Organization Science, 1(3), 267-292.

[26] Ray, S. and Cardozo, R. 1996. Sensitivity and creativity in entrepreneurial opportunity recognition: a framework for empirical investigation. Sixth Global Entrepreneurship Research Conference, Imperial College, London.

[27] Sarasvathy, S.D. 2001. Causation and effectuation: Towards a theoretical shift from economic inevitability to entrepreneurial contingency. Academy of Management Review, 26: 243-288.

[28] Sarasvathy, S. D., Venkataraman, S., Dew, N., \& Velamuri, R. 2003. Three Views of Entrepreneurial Opportunity. In Z. J. Acs \& D. B. Audretsch (Eds.), Handbook of Entrepreneurship Research: An Interdisciplinary Survey and Introduction, 141-160. London: Kluwer Academic.

[29] Shane, S. 2000. 'Prior knowledge and the discovery of entrepreneurial opportunities,' Organization Science, 11(4), 448-469.

[30] Stake, R.E., 1995. The art of case study research, Sage Publications.

[31] Van de Ven, A., Engleman, R. 2004. Event- and Outcome-Driven Explanations of Entrepreneurship. Journal of Business Venturing, 19(3): 343-358.

[32] Vaghely, I.P., and Julien, P-A. 2010. Are opportunities recognized or constructed?: An information perspective on entrepreneurial opportunity identification. Journal of Business Venturing, 25(1), 73-86.

[33] Venkataraman, S. 1997. 'The distinctive domain of entrepreneurship research,' in Advances in Entrepreneurship, Firm Emergence and Growth. Eds J. Katz and R. Brockaus. Greenwich, CT: JAI Press, 119-138.

[34] Waters, B., 2005. Software as a service: A look at the customer benefits. Journal of Digital Asset Management, 1, 32-39.

[35] Yin, R.K., 2009. Case study research: Design and methods. CA: SAGE Publications.

[36] Zhang, Q., Cheng, L., Boutaba, R., 2010. Cloud computing: state-of-the-art and research challenges. Journal of Internet Services and Applications, 1(1), 718.
[37] Gens, F., 2009. Defining "Cloud Services" -an IDC update. IDC exhanges. blogs.idc.com/ie/?p=422.

[38] Liebenau, J., Kärrberg, P. Grous, A., Castro, D. 2012. Modelling the cloud: employment effects in two exemplary sectors in the United States, the United Kingdom, Germany and Italy. LSE-Enterprice, London School of Economics and Political Science, UK. 